persisted in permanent darkness. The phases of induced rhythms could, however, be shifted by sudden changes in temperature provided these exceeded certain threshold values. Delays caused by extreme cooling persisted in darkness and were additive. Individual crabs in which melanophore rhythms of different phase had been induced kept them side by side when transferred to the same darkened aquarium. In spite of this independence of phase it was observed that the amplitude of the melanophore changes was increased by the presence of other fiddler crabs of the same or another species.

Among the papers circulated but not read, that by K. Hoffman (Wilhelmshaven) dealt with the influence of temperature and pretreatment on the 24-hr. motor activity of lizards ; Y. Ondo's (Tottori, Japan) with the responses of shore sowbugs to the periodic movement of waves; E. Szirmay's (Budapest) described some uses of the comparative study of muscle rhythms, and L. S. Copelman's (Bucharest.) dealt with some of the philosophical aspects of biological time.

The International Society for the Investigation of Biological Rhythms, to give it its original name, has now been in existence for twenty years, and at its six conferences a considerable part of the field has been surveyed. More recently the elaboration of general methods for the investigation of bio-rhythms and the formulation of a unifying theory have been attempted.

It is hoped that the full text of the papers will shortly be published. The Society has been invited by Dr. A. Caniggia (Siena) to hold its seventh conference in 1960 in Italy. Inquiries concerning the proceedings, membership and other matters should be addressed to Dr. A. Sollberger, Department of Anatomy, Karolinska Institutet, Stockholm.

H. Kalmus

\section{FLAMMABILITY OF TEXTILES}

$I^{\mathrm{N}}$ $N$ the past few years an increasing amount of publicity has been given to accidents resulting from the burning of elothing, and in the United States legislation has been introduced to prohibit the sale of certain very inflammable types of fabric. In the United Kingdom various safety committees have been set up, and a valuable report on the flammability of apparel fabrics in relation to domestic burning accidents has been published by the British Standards Institution*. It was not surprising, therefore, that the one-day conference, organized by the Textile Institute and dealing with the flammability of textiles, attracted a great deal of attention, for this was probably the first time that mombers of the textile industry, of the distributory trades and of the public were able to meet and discuss together the many aspects of the problem. The conference was held at the laboratories of the Rayon Research Association in Manchester on October 15, and was opened by the president of the Textile Institute, Sir Ernest W. Goodale.

It was evident from the substance of the four papers which formed the basis of the Conference that the seriousness of the high inflammability of certain textiles is widely appreciated and that the textile

- British Standards Institution: PD 2777 (1957). industry is anxious to overcome this hazard. Progress in dealing with the problem has in the past been hindered by lack of precise information, and perhaps the most important feature of the conference was the dissemination of reliable data to replace the lore which is often associated with anything that has to do with fire.

Mr. D. I. Lawson, of the Joint Fire Research Organization, summarized valuable data on the incidence of burning accidents, and his paper emphasized several unexpected observations. Of particular seriousness to the textile industry was the statement that burns involving elothing had the highest mortality-rate of any kind of burn, and that four out of five of the total accidents reported occurred in the home. This is in spite of repeated warnings of the danger from unguarded fires. It was indeed surprising to learn that only half the parents of young children ques. tioned in an investigation had a fireguard. Mr. J. S. Ingham, of Messrs. Marks and Spencer, Ltd., who dealt with the economic aspects of fireproofing and with the possibility of being able to sell fire-proofed garments, also stressed the dangers associated with flared-out dresses and particularly with children's nightdresses made from winceyette.

All the speakers and many members of the conferonce agreed on the need for a publicity campaign to encourage the use of fireguards in homes whore there are young children, and to popularize close-fitting night wear. Mrs. Jean Mann, M.P., speaking from the floor, suggested that the provision of fireguards should be made a condition of house le tting.

The other solution, with which the textile and chemical industries are more directly concerned, is, of course, the provision of safe fabrics. It is difficult to define a 'safe' fabric, for the textile industry and the public must be in agreement about this. One of the first problems, therefore, is to devise a test for inflammability which has some rolation to the practical hazards usually met with. Several of the suggested methods were discussed in detail by Mr. F. Ward, of Courtaulds, Ltd. Mr. Lawson thought that it would be unnecessarily stringent to define as safe only those fabrics which would not ignite when exposed to a radiant source of energy similar to that emitted from the surface of open fires. Measurement of the vertical speed of flamo propaga. tion was generally regarded as being more satisfactory because this gives the length of time available to extinguish the flame or to discard a burning garment. Apparatus for measuring this was described and the term 'flame resistance rating', defined as the time for flame to be propagated 100 in. vertically, was used for expressing the results obtained. Dr. T. H. Morton, of Courtaulds, Ltd., provided a great deal of useful information on how the flame resistance rating is affected by the composition, construction and weight of the fabric, and by the use of special procosses, including some of the modern fireproofing finishes. There are many finishes which will reduce flammability, but for general acceptance other characteristics such as permanence of the proof and the feel of the cloth have also to be considered. 'There was general agreement that any proof used for children's nightdresses should givo flame resistance throughout the life of the garmont, that is, the effect should not be removed by as many as fifty washes.

Clearly one of the most difficult tasks is to define a safe value for the flame resistance rating. Mr. 
Lawson suggested that a safe level should be well away from the level associated with the recent run of burning accidents, but not so high as to eliminate more types of fabric and flame retardant treatments than necessary. It was recommended that fabrics with a durable flame resistance rating of greater than 150 should be warranted as flameproof and identified as such. Most of the manufacturers of durable flame proofs are confident of being able to meet this standard, and many useful unproofed fabrics would be rogarded as being safe.

The discussion by members of the conference was particularly stimulating, and included contributions from Dr. J. B. Bull, who has been intimately concerned with surveys made by the Burns Unit of the Medical Research Council, and from Mrs. Jean Mann, M.P., Mrs. F. P. A. MeLaughlin, M.P., and Mr. Hervey Rhodes, M.P., all of whom are well known for their interest in the problems of safety and textiles.

The goneral conclusion from the conference was a unanimous agreement on the need for an intensified safety campaign at national level and for providing safe fabrics. Although many of the fabrics at present regarded as dangerous can be made safe by troatment with reagents such as tetrabishydroxymethyl phosphonium chloride, antimony oxide, and mixtures of antimony and titanium oxides, it was rocognized that a need still exists for cheaper durable treatments. Members of the conference, particularly the chemists and textile finishers, left greatly encouraged, knowing that the difficult problems with which they have to deal are sufficiently important to demand maximum effort and imagination.

C. S. WHEWELT

\section{THE ROCKEFELLER FOUNDATION}

$\mathrm{N}$ the Rockefeller Foundation annual report, 1956, I the President's review, reprinted with a summary of the Appropriations Account and Principal Fund and a list of appropriations made in 1956, notes that for the year the appropriations totalled $30,075,305$ dollars, the largest for any one year since the Founda. tion was established in 1913. Of this total, $5,963,605$ dollars were for the humanities, 5,501,100 dollars for biological and medical research, $4,877,400$ dollars for agriculture, 4,290,605 dollars for medical education and public health and 3,290,260 dollars for social sciences. For the fellowship programme, under which 458 individuals from 47 countries held fellowships in 1956, 2,025,000 dollars were appropriated.

In his review Dean Rusk stresses three features of the year's activities. First, noting that nineteen of the present eighty-one member States of the United Nations, with a population of more than 650 millions, have emerged as fully independent nations since the Second World War, he emphasizes that the officers and trustees of the Foundation believe that peace and orderly economic growth in the world during the next twenty-five years will be decisively influenced by what happens in these independent nations of Africa, the Middle East and Asia. Peace and stability will gain enormously if they establish constitutional systems with friendly and easy exchange with the rest of the world, increasingly productive economies, and educational systems which can train leaders in adequate numbers and educate their citizens for the responsibilities of their now societies. To enable the Foundation's ex- penditure on Latin America, Asia, the Middle East and Africa to be sharply increased without a large reduction of expenditure in the United States and Europe, the Trustees have decided to draw on capital funds for several years. During 1956 some 6 million dollars were allocated to the expanded programme, over and above the normal allocations to these areas from income.

Secondly, the President reviews at some length the Foundation's responsibilities in the nuclear age, commencing with its grant in 1940 toward the construction of a 184-in. cyclotron at the University of California, Berkeley. The report suggests that there are three main directions in which the resources of the Foundation can be usefully applied, taking into account the very large sums available from government and industry. The first is the public health aspects of nuclear energy, broadly conceived and for study of the effects of radiation on man. For the formulation of questions upon which further research is urgently noeded the Foundation has already made grants to the National Academy of Sciences totalling 275,000 dollars. The second is in the Foundation's traditional support of basic scientific research with the main emphasis upon the living processes. Here, the nine grants for research in genetics made during the year totalled 991,000 dollars, the largest, 350,000 dollars, being to the University of Indiana, while 260,000 dollars went to the University of Copenhagen, 61,000 dollars to the National Centre for Scientific Research, Paris, 50,000 dollars to the Institute for Human Genetics, Upsala, and 24,000 dollars to the London Hospital Medical School. A third type of study for which Foundation support is planned, on a selective basis, is that of the economic, legal and political problems of the nuclear age, with special reference to the increasingly complex issues of international relations, with which nuclear energy is now inextricably bound up. About a dozen grants have been made to young professors in universities throughout the United States studying a wide range of contemporary political problems. The Foundation also hopes to assist a few mature scholars to embark on, or to complete, significant research in this field, to encourage institutes to undertake objective studies of international political problems, to stimulate the growth of organized knowledge and theories of foreign policy, including the techniques and principles involved in its conduct.

The third aspect of the year's activities emphasized by Dean Rusk is the assistance given to Hungarian scientists, scholars and students. To this refugee problem the Foundation in late 1956 and early 1957 devoted more than 1,200,000 dollars, almost 700,000 dollars of which went to the institutions in Austria which bore the brunt.

In the field of medical education and public health considerable attention was paid to professional education, grants for which included 367,400 dollars to the Christian Medical College, Vellare; 299,750 dollars to King George's Medical College, Lucknow ; 273,300 dollars to Seth Gordhandas Sunderdas Medical College, Bombay ; 570,000 dollars to the University of the Andes, Bogotá; 215,000 dollars to the Recife Medical School, Brazil ; 290,000 dollars to the School of Medicine, Keio University, Tokyo ; and 100,000 dollars to the Department of Child Health, University of Ankara. A grant of 163,280 dollars was made to provide four years support for studies of population dynamies in Indian villages jointly by Harvard 